\title{
INFLUENCE OF KNITS STRUCTURE ON FLAMMABILITY AND COMFORTABILITY
}

\author{
D. Mikučionienè*, L. Milašiūtè, R. Milašius
}

Department of Mechanical Engineering, Kaunas University of Technology, Studentu 56, LT-51424 Kaunas, Lithuania

E-mail: daiva.mikucioniene@ktu.It

\begin{abstract}
:
Investigations of the influence of the knit structure, i.e. the loop length and the number of yarns in a loop, on flammability and comfortability are presented in this paper. The investigations were carried out using single jersey knits from Delta TA 18 tex $\times 2$ yarns with five variants of a loop length. Single yarn as well as folded yarn from two single yarns was used in the investigations. Comparison of the results of single-layer knits flammability and air permeability with those of multilayer packet was made. The results obtained show that an increase in the loop length of the knit increases their permeability to air and decreases the burning time as well as increase in the number of layers decreases the air permeability and increases the burning time. Moreover, the similar burning time with significantly different permeability to air can be achieved changing the basic knitting parameters, i.e. the loop length and/or the yarn linear density.
\end{abstract}

\section{Keywords:}

weft knit, loop length, tightness factor, flammability, air permeability, comfortability, multilayer packet.

\section{Introduction}

In recent years, the safety and comfort of human beings has become an important issue. Growing of the functional textiles industry has, therefore, been involved in a number of new developments in fibres and fabric structures. In protective clothing, the low propensity for ignition from a flame source and, if the item ignites, a slow spread are essential. The most direct way to improve the safety of firefighters is creation of protective clothing with two functions: be flame resistance and form a heat barrier and be comfortable.

Structural and mechanical properties of knitted fabrics are very important in many ways. The fire-protection level depends on the structure, raw material and fits of the protective garment [1,2]. Thermal and flame protection properties also depends on the construction of clothing, i.e. on the number of textile layers in the packet used in a garment. A garment packet contains air interlayer between the fabric layers [3-4]. In references [5-6], it is stated that even very thin additional layer of textile increased the thermal and flame protection of garment. High thermal protection can be achieved by wearing multilayer or thick textile materials, but this prevents good ventilation and so creates high heat stress to wearers, reducing their work efficiency in battles against wild fires [6]. Also, the higher air permeability increases the usage comfortability [7-11] which is very important for users, and especially for head garments - masks. Not only excellent heat protection but also good moisture comfort is necessary when firefighters wear protective clothing during firefighting; they cannot work efficiently if they feel uncomfortable [12].
To overcome thermal and flame hazards, heat- and flameresistant fibres are used to produce thermal protective clothing. Generally, meta-aramids are used in intense heat-protective clothing. A blend of Nomex and Kevlar (Nomex Delta TA) is preferred to provide a greater mechanical stability to char. The structures of clothing used are very different. For manufacturing of woven fabrics, usually plane and twill 2/1 weaves are used, whereas for knitted fabrics, usually single jersey and rib patterns are used. Knitted fabrics are used for firefighters, Special Forces, racers' masks, gloves, socks and other kinds of clothing manufacturing [13].

Knitted fabrics provide outstanding comfort and log time is preferred in many types of clothing. The main advantages of knitted fabrics lie in their low cost, improved barrier properties and comfort properties. They possess high extensibility under low load, allowing comfortable fit on any part pulled, are lightweight and are flexible. Knitted fabrics are commonly used for firefighters' underwear, socks, gloves and helmet liners because of their excellent mechanical and comfort properties [14]. Designing of a new fabric requires predicting its behaviour before the manufacturing of the fabric. Therefore, investigation on the influence of various parameters on fabric properties and creation of a fabric design in accordance with the characteristics of relationships determined are very topical. The design of firefighter clothing is a compromise between protection and comfort.

The main goal of this work was to find the optimal relation between the low flammability and high comfortability of a garment from knitted fabric by changing the structural parameters of the knitted fabric. 


\section{Materials and Methods}

To define the influence of the structural properties of knit on flammability and comfortability, the loop length was estimated and tightness factor was calculated. Two groups of knits are made in a single jersey pattern on a single-bed 14E gauge weft knitting machine from Nomex Delta TA yarns, which are used for fire-protective clothing manufacture. The knits of first group $A$ are knitted from Nomex Delta TA yarns with 18.5 tex $\times 2$ linear density, and the other one $B-$ from Nomex Delta TA yarns with 18.5 tex $\times 2 \times 2$ linear density. In both groups, five variants of knits with different loop lengths $(4.80$ $5.01,5.72,6.32$ and $6.90 \mathrm{~mm}$ ) were manufactured. The main structural parameters of the knits tested are presented in Table 1.

Three combinations of packets from group $A$ (a single layer of knit, two layers of single knit, four layers of single knit) and two combinations of packets from group $B$ (a single layer of knit, two layers of single knit) were used in the investigations of flammability and air permeability.

Structural parameters of the knits were analysed according to British Standard BS 5441:1998. The tightness factor TF was calculated by the following equation:

$$
T F=\frac{\sqrt{T}}{L}, \operatorname{tex}^{1 / 2} \mathrm{~cm}^{\square 1},
$$

where $T$ is the linear density of the yarn in tex and $L$ is the loop length in $\mathrm{cm}$.

The flammability of the knits was investigated using the horizontal test method according to standard DIN 50050$1: 1989$, which is applicable to all textile materials. In accordance with the procedure, a fabric specimen was clamped wrinkle free between two plates in a horizontal position. The horizontal flammability test was used, and the burning time from the start until knit break-up was measured. The height of the flame was $4 \mathrm{~cm}$ and the distance between the flame source and materials investigated was $2 \mathrm{~cm}$. Average values of the tests were calculated from the five measurements.
The air permeability of the knits was investigated according to the standard EN ISO 9237:1997 using a head area of $10 \mathrm{~cm}^{2}$ and a pressure difference of $100 \mathrm{~Pa}$. Average values of the tests were calculated from the 10 measurements. The air permeability $R$ was determined according to the equation:

$$
R=\frac{D}{A} \cdot 167, \mathrm{dm}^{3} /\left(\mathrm{m}^{2} \mathrm{~s}\right),
$$

where $D$ is an average of air flow rate, $\mathrm{dm}^{3} / \mathrm{min}$, and $A$ is the operative area of sample equal to $10 \mathrm{~cm}^{2}$.

The coefficients of variation for all the tests did not exceed $9 \%$.

\section{Results and discussions}

The experiments were carried out with one, two and four layers of knits of variants $A 1-A 5$, and with one and two layers of knits of variants $B 1-B 5$ (see Table 1). The flammability of the knitted fabrics was estimated by investigating the burning time from the start until the knit breaks-up. The results of investigation are presented in Figure 1.

The results of the burning time show evidently the high influence of the number of yarns in the loop (variants $A$ and $B$ ) and the number of layers in the packet on the burning time. The burning time (as well as protective properties) increases when the number of yarns in the loop and the number of layers in the garment packet increase. The same tendencies were also observed in our earlier investigations [13]. The burning time of one layer of knits of variant $A$ is $2-3$ times lower than that of variant $B$ knits that are knitted of yarns with twice higher linear density. The same ratio is observed for two layers of variant $A$ and variant $B$ knits. The experimental results also confirmed the statement that one layer of the knit with two yarns in the loop has better protective properties against fire than two layers of the knit with one yarn in the loop.

The dependence of burning time on the loop length is presented in Figure 2. The burning time depends on the loop length linear. The coefficients of determination of the line

Table 1. Main characteristics of knits tested.

\begin{tabular}{|c|c|c|c|c|}
\hline Sample variant & Yarn linear density (tex) & Loop length $\mathbf{( m m})$ & Area density $\left(\mathbf{g} / \mathbf{m}^{2}\right)$ & Tightness factor (tex1/2/cm) \\
\hline$A 1$ & $18.5 \times 2$ & $4.80 \pm 0.03$ & $135 \pm 3$ & 12.67 \\
\hline$A 2$ & $18.5 \times 2$ & $5.01 \pm 0.02$ & $126 \pm 5$ & 12.16 \\
\hline$A 3$ & $18.5 \times 2$ & $5.72 \pm 0.04$ & $111 \pm 6$ & 10.65 \\
\hline$A 4$ & $18.5 \times 2$ & $6.32 \pm 0.06$ & $106 \pm 8$ & 9.64 \\
\hline$A 5$ & $18.5 \times 2$ & $6.90 \pm 0.07$ & $92 \pm 7$ & 8.83 \\
\hline$B 1$ & $18.5 \times 2 \times 2$ & $4.80 \pm 0.02$ & $317 \pm 3$ & 17.92 \\
\hline$B 2$ & $18.5 \times 2 \times 2$ & $5.01 \pm 0.03$ & $299 \pm 3$ & 17.17 \\
\hline$B 3$ & $18.5 \times 2 \times 2$ & $5.72 \pm 0.03$ & $270 \pm 5$ & 15.03 \\
\hline$B 4$ & $18.5 \times 2 \times 2$ & $6.32 \pm 0.02$ & $246 \pm 4$ & 13.61 \\
\hline$B 5$ & $18.5 \times 2 \times 2$ & $6.90 \pm 0.02$ & $216 \pm 3$ & 12.76 \\
\hline
\end{tabular}




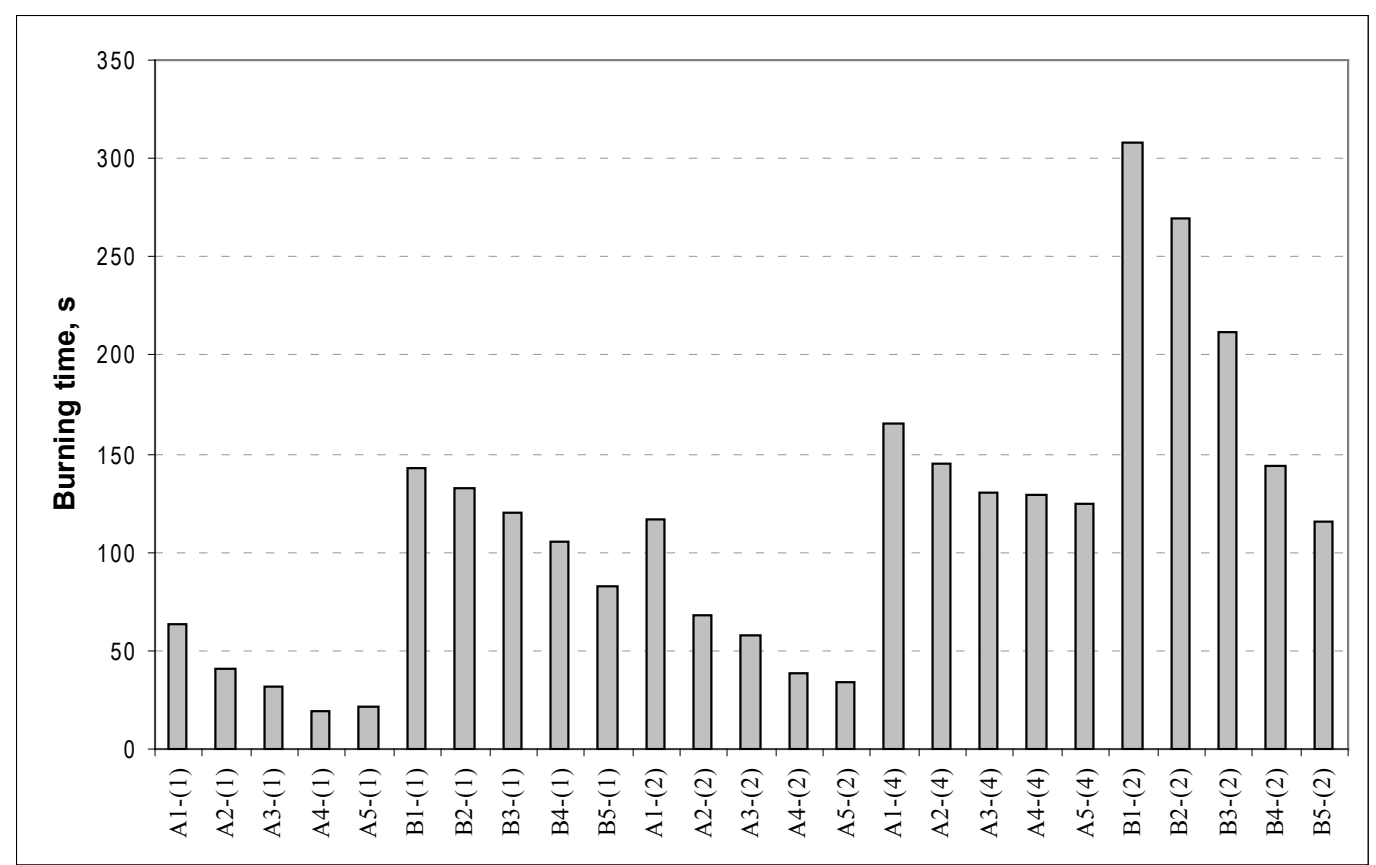

Figure 1. The influence of loop length, number of yarns in the loop and number of layers in the packet on burning time.

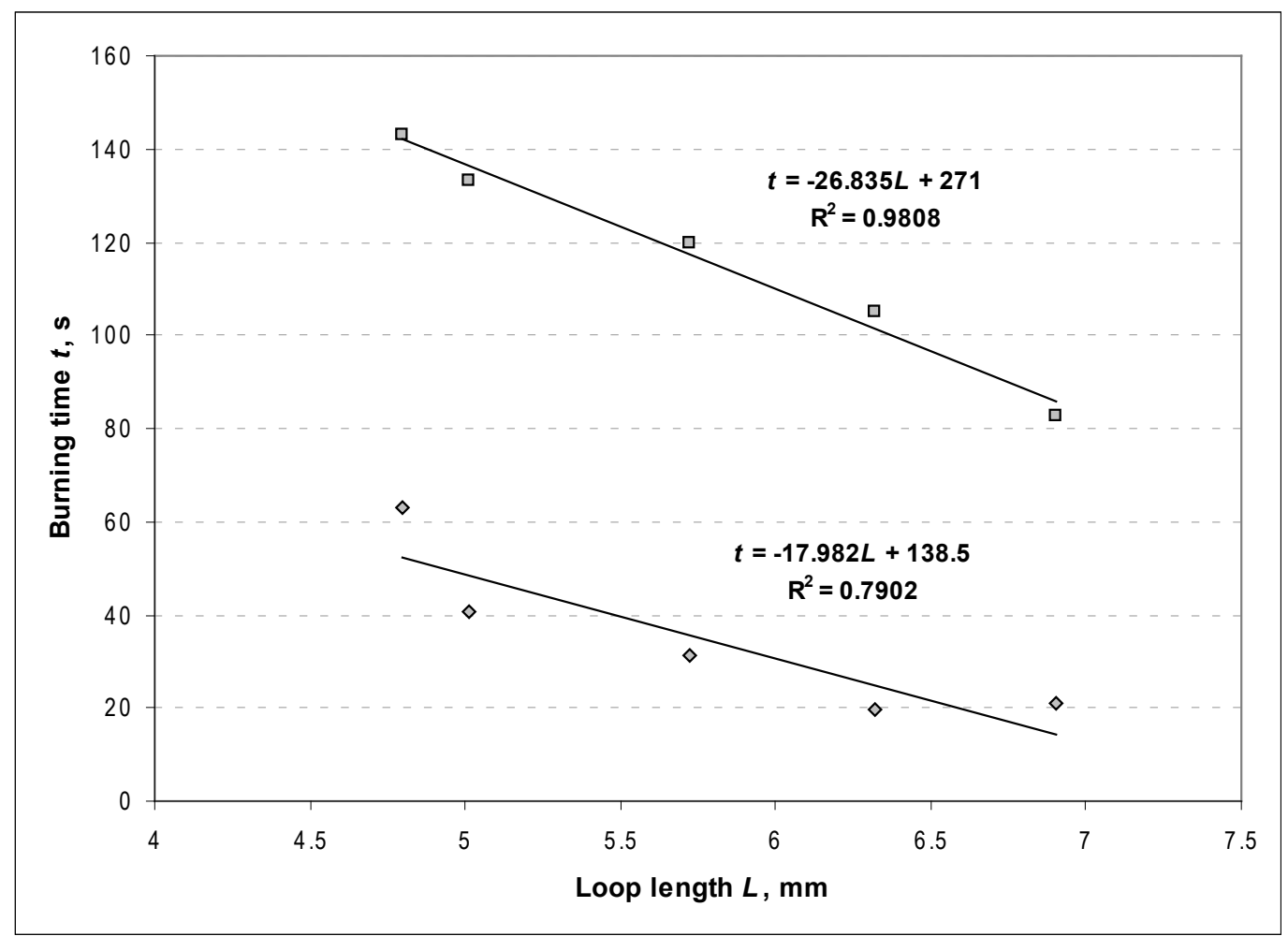

Figure 2. Dependence of burning time on the loop length (lower line for the variant $A$ and upper line for the variant $B$ )

are equal to 0.9808 and 0.7902 , meaning that a correlation between these two characteristics exists. By increasing the loop length in $45 \%$, the burning time of the knits of variant $A$ decreases in $\sim 40$ seconds and of the knits of variant $B$ in $\sim 60$ seconds. This is because of the phenomenon that when the loop length as well as the porosity of a knit increases, the burning time decreases. And this phenomenon is more intense in knits with higher linear density of yarns. Therefore, to increase the protective properties against fire, the loop length should be as low as possible. On the other hand, to what degree this will worsen comfort properties, such as air permeability?
The influence of the loop length of the knits investigated, number of yarns in the loop and number of layers in the packet on permeability to air is presented in Figure 3 . It is well known that air permeability increases by increasing the loop length in the knit. This is definitely demonstrated by the histogram of the results obtained in Figure 3 and the linear relationship with high coefficients of determination $(0.9963$ and 0.9622 ) in Figure 4. It is also visible from the results presented in Figure 3 that using two yarns in the loop instead of one, permeability to air decreases $2-4$ times depending on the loop length. It is interesting that the increase of yarns in the loop decreases permeability to air much more than the 


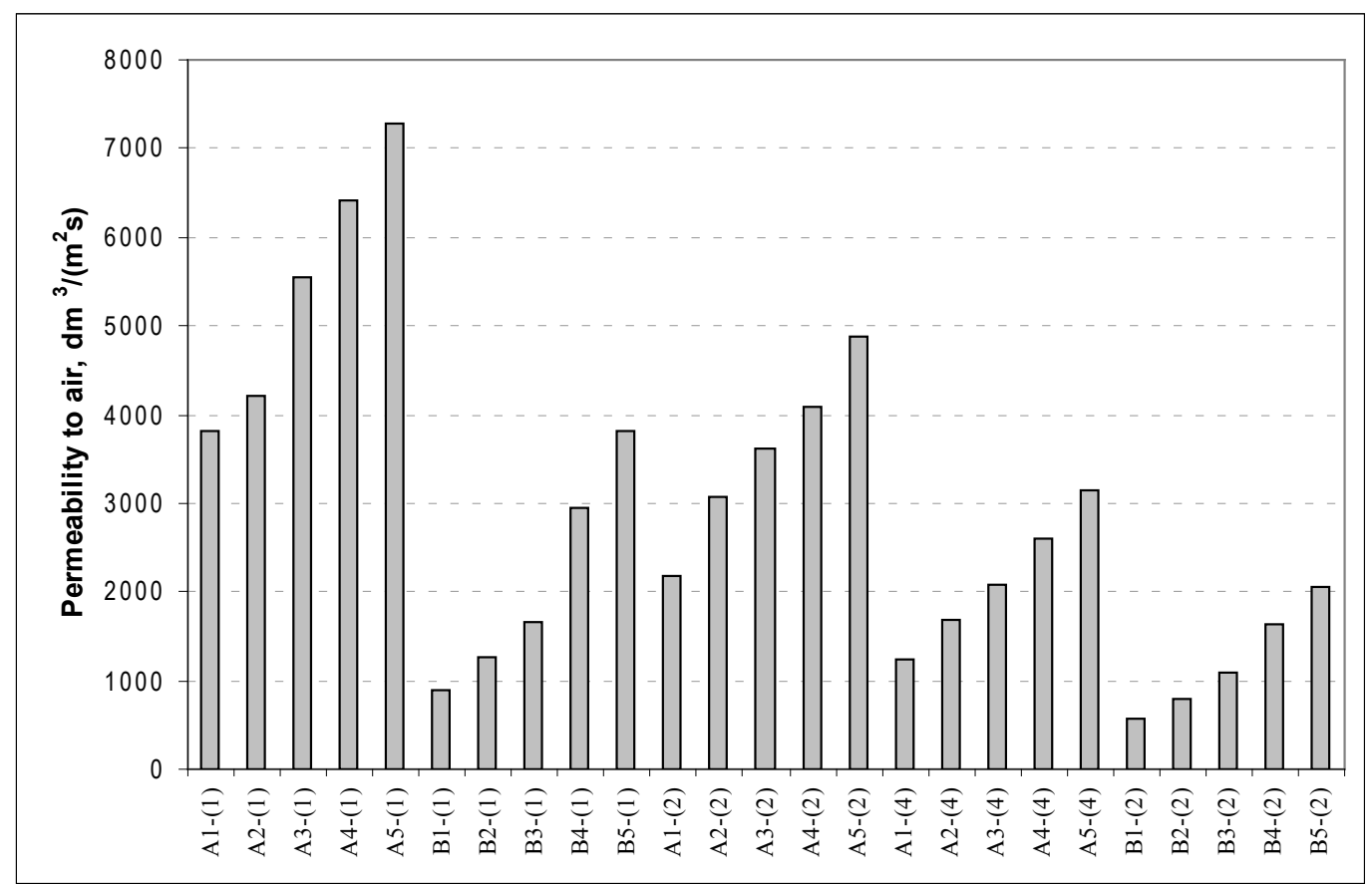

Figure 3. The influence of loop length, number of yarns in the loop and number of layers in the packet on permeability to air.

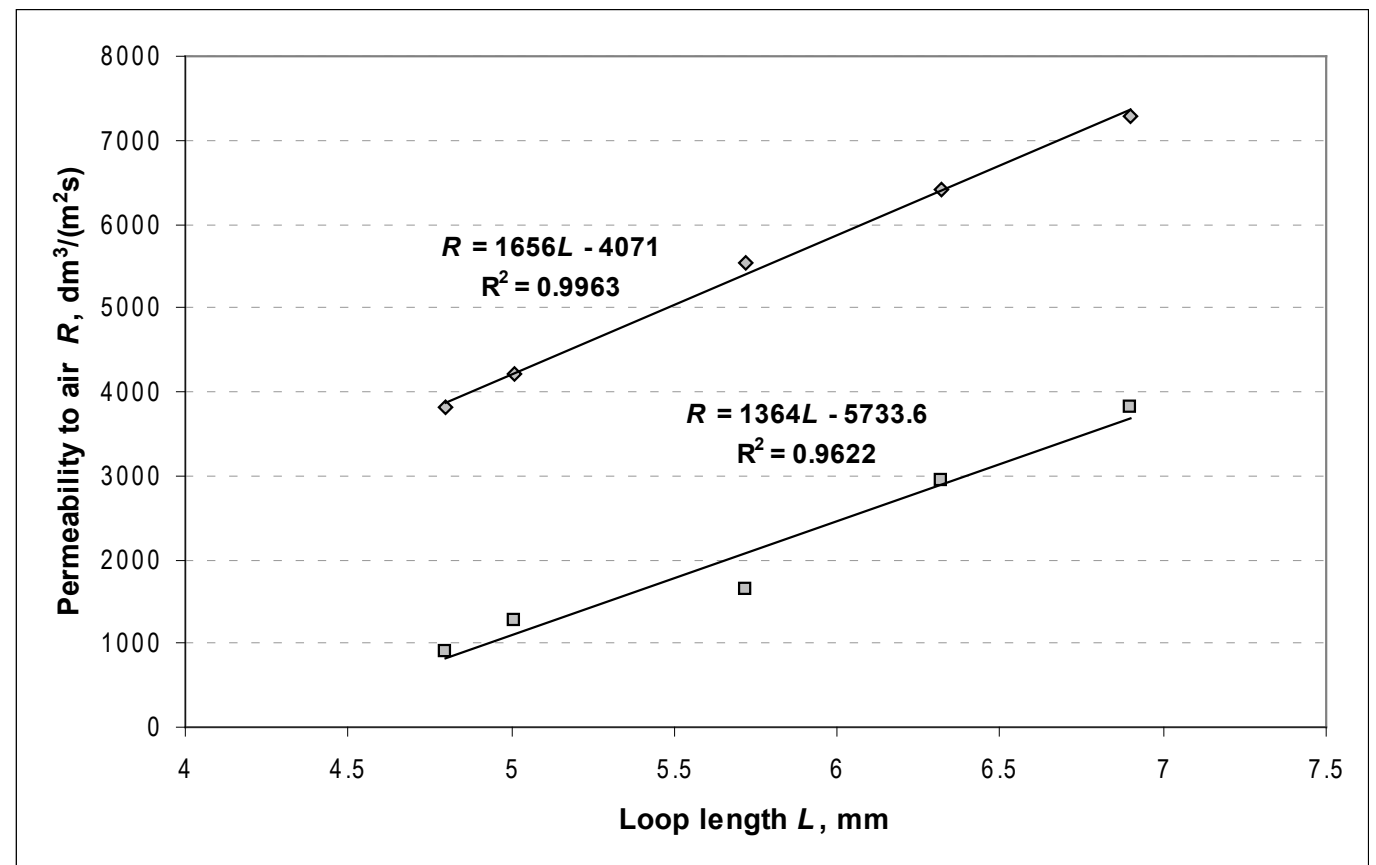

Figure 4. Dependence of permeability to air on the loop length (upper line for the variant $A$ and lower line for the variant $B$ ).

increase of the layers in the packet. Air permeability through one layer of knit made of two yarns in the loop is lower than through the packet of four layers of knits made of one yarns in the loop.

The number of yarns in the loop (i.e. the total linear density of the yarn) and the loop length are linked together in the rate named as tightness factor. The tightness factor TF is defined as the ratio of the area covered by the yarn in one loop to the area occupied by that loop. The tightness factor indicates the relative tightness or looseness of plain weftknitted structures. For most weft-knitted fabrics and wide range of yarns, the tightness factor ranges between 10 and 20 tex $^{1 / 2} \mathrm{~cm}^{-1}[15]$.
Correlation between the tightness factor of knits investigated and the burning time and permeability to air is presented, respectively, in Figures $\mathbf{5}$ and $\mathbf{6}$.

It is evident, this is also confirmed by the results presented in [13], that by increase of tightness factor (the tightness of the knit) the burning time increases and permeability to air decreases. However, the most important is the fact that this investigation demonstrates the evident different zones of the correlation between the tightness factor and burning time or air permeability. The highest influence of the tightness factor alteration on the burning time is in the zone of 12$13 \mathrm{tex}^{1 / 2} \mathrm{~cm}^{-1}$, the recommended tightness factor for single jersey knits (see Figure 5). The alterations of tightness 


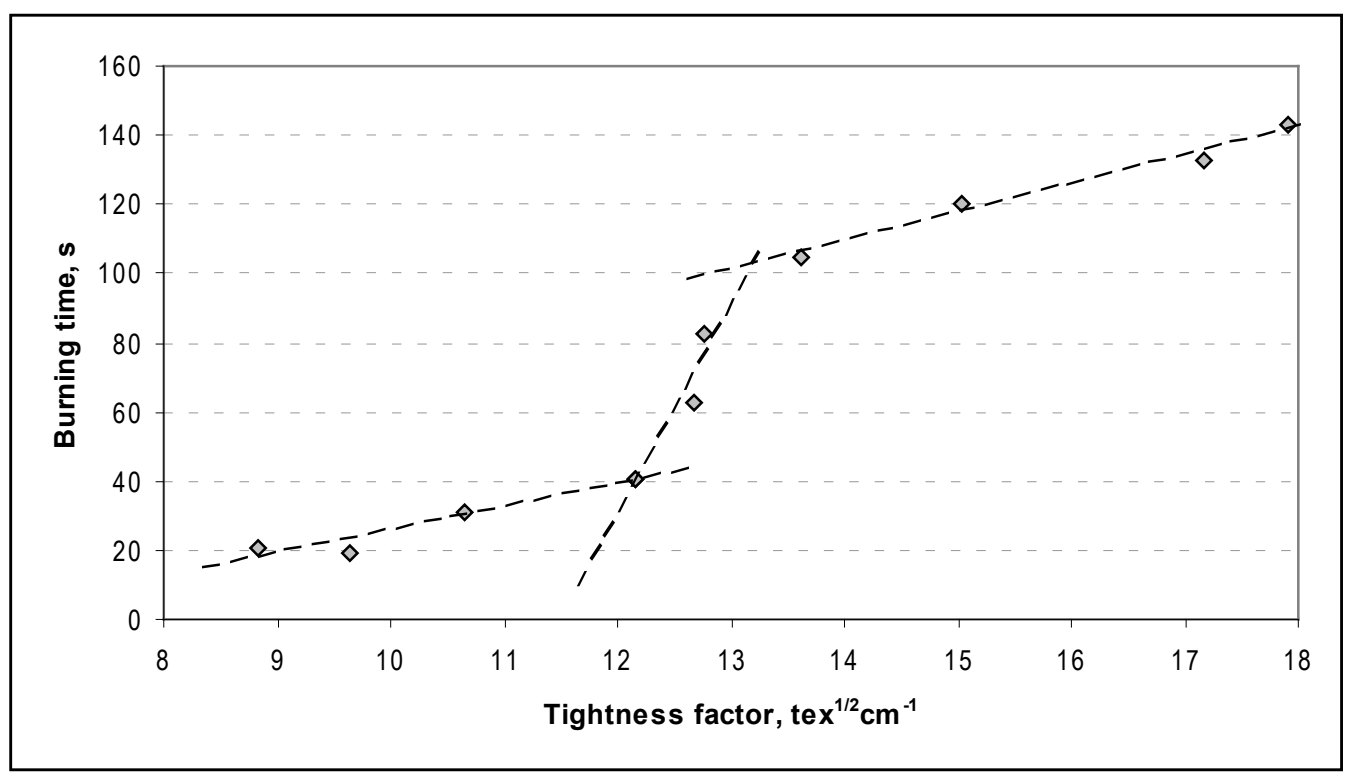

Figure 5. Correlation between tightness factor and burning time.

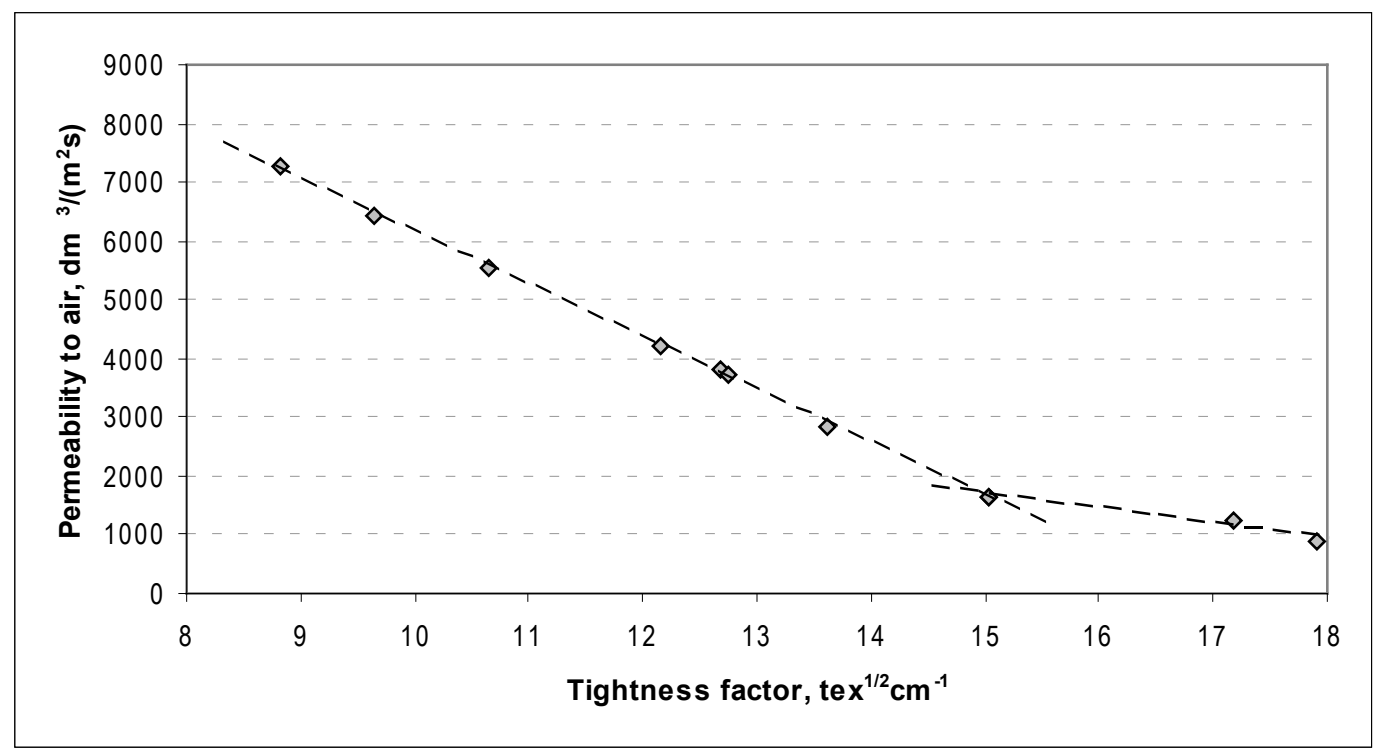

Figure 6. Correlation between tightness factor and permeability to air.

factor until 12 tex $^{1 / 2} \mathrm{~cm}^{-1}$ and after 13 tex $^{1 / 2} \mathrm{~cm}^{-1}$ influence the burning time much less.

There are two zones of the correlation between the tightness factor and permeability to air presented in Figure 6 . The alterations of the tightness factor until 15 tex $^{1 / 2} \mathrm{~cm}^{-1}$ have higher influence on the permeability to air than alterations after $15 \mathrm{tex}^{1 / 2} \mathrm{~cm}^{-1}$. It is evident that when the structure of the knit becomes tight, the porosity of the knit becomes very low and the increasing of the loops density cannot influence air permeability in a high degree.

The correlation between air permeability and the burning time is presented in Figure 7. The wider number of experiments with the higher number of knitted specimens evaluating the loop length, number of yarns in the loop and number of layers in the packet demonstrates that the high correlation between air permeability and the burning time was not obtained, contrary to the results presented in [13]. From the results presented, it can be seen that three different zones of correlation were investigated. For one layer of single jersey knits variant $A$ (with a linear density of yarn 18.5 tex $\times 2$ and the loop lengths $5 \mathrm{~mm}$ and more) air permeability is very high, i.e. more than 4000 $\mathrm{dm}^{3} /\left(\mathrm{m}^{2} \mathrm{~s}\right)$, but the burning time is less than $50 \mathrm{~s}$. In this zone, the alteration of air permeability in the ranges of 4000-7500 $\mathrm{dm}^{3} /\left(\mathrm{m}^{2} \mathrm{~s}\right)$ influences the burning time of the knits investigated only in few percents. In the other zone the burning time higher than $212-312 \mathrm{~s}$, air permeability $580-1100 \mathrm{dm}^{3} /\left(\mathrm{m}^{2} \mathrm{~s}\right)$ depend on the packets from the two layers of knits variant $B$ (with two yarns in the loop (18.5 tex $\times 2 \times 2$ linear density) and loop length $4.8-5.7 \mathrm{~mm})$. In this zone, when burning time increases approximately twice, air permeability decreases only in few percents. The most interesting is the third zone with the burning time $50-150 \mathrm{~s}$ and air permeability $1000-4000 \mathrm{dm}^{3} /\left(\mathrm{m}^{2} \mathrm{~s}\right)$. In this zone we cannot see the evident correlation between air permeability and the burning time. However, areas with the very similar permeability to air but significantly different burning time and vice versa can be found in this zone. 


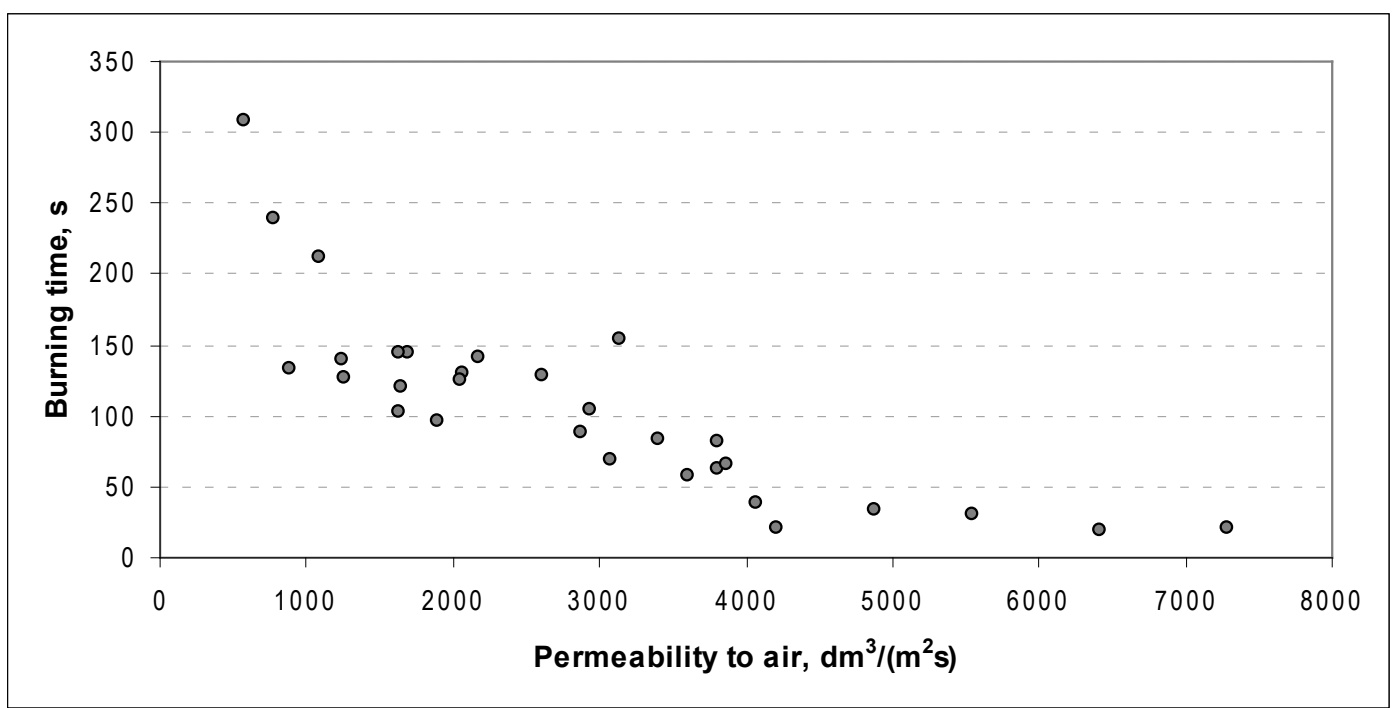

Figure 7. Correlation between air permeability and burning time.

Therefore, it can be concluded that the influence of structural parameters on protective and comfort properties is evident and very high. Consequently, the mentioned properties can be changed effectively only by changing the structural parameters. It must be definitely appreciated in the designing of new textile products because the changing of the structural parameters of a new designed product is the cheapest and the simplest way to achieve the best required result. And only when the result cannot be achieved through the structure, the more expensive and sophisticated methods should be used. Unfortunately, in recent times there is a tendency that the structural investigations are forgotten, narrowing to simplest patterns of knitted or woven fabrics and not estimating the significance of their structural parameters.

\section{Conclusions}

A higher density of loops in a knit, a higher number of yarns in the loop as well as a higher number of layers in the packet increase the burning time of a garment and decrease its permeability to air.

One layer of a knit with two yarns in a loop has better protective properties against fire than two layers of the knit with one yarn in a loop.

A burning time and air permeability of a knit can be predicted depending on the tightness factor of a knit. By increasing the tightness factor (the tightness of the knit) the burning time increases and the permeability to air decreases. Very important is the fact that evident different zones of the correlation between the tightness factor and burning time or air permeability were obtained in this investigation. The highest influence of the tightness factor alteration on the burning time was found in the zone of $12-13$ tex ${ }^{1 / 2} \mathrm{~cm}^{-1}$, the recommended tightness factor for single jersey knits. Also, two zones of the correlation between the tightness factor and permeability to air were obtained. The alterations of the tightness factor until $15 \mathrm{tex}^{1 / 2} \mathrm{~cm}^{-1}$ of the knits investigated have higher influence on air permeability than alterations after this value, while the structure of a knit is tight and its porosity is very low.

A high correlation between air permeability and the burning time was not obtained. Three different zones of correlation investigated were obtained in this research. In the case of multilayer packet of tightly knitted fabrics, burning time increases approximately twice and air permeability decreases only in few percents. In the case of one layer of loose knitted fabrics, the alteration of air permeability in approximately two times influences the burning time of knits investigated only in few percents. And the most important is the third zone, where areas with the very similar permeability to air but significant different burning time can be found, and vice versa. It means it is very simple to increase comfortability of a knit without decreasing its flammability only by changing the knit structure.

It can be concluded that the influence of structural parameters on protective and comfort properties of knitted garments is very high.

\section{Acknowledgements}

The authors acknowledge the contribution of the 7FP 2BFUNTEX and COST Action MP1105.

\section{References}

[1] Ertugrul, S., Ucar, N. (2000) Predicting Bursting Strength of Cotton Plain Knitted Fabrics using Intelligent Techniques. Textile Research Journal, 70 (10), 845-851.

[2] Das, A., Alagirusamy, R., Kumar, P. (2011) Study of Heat Transfer through Multilayer Clothing Assemblies: A Theoretical Prediction. AUTEX Research Journal, 11 (2), 54-60.

[3] Gilewicz, P. et al. (2013) Change in Structural and Thermal Properties of Textile Fabrics Packages Containing Basalt Fibres after Fatique Bending Loading. Fibres\&Textiles in Eastern Europe, 21 (5), 80-84. 
[4] Zhu, G. et al. (2014) An Analysis of Effective Thermal Conductivity of Heterogeneous Materials. AUTEX Research Journal, 14 (1), 14-21.

[5] Nadzeikiené, J. et al. (2006) Evaluating Thermal Insulation Properties of Garment Packet Air Interlayer. Fibres\&Textiles in Eastern Europe, 14 (1), 52-55.

[6] Sirvydas, P.A. et al. (2006) The Role of the Textile Layer in the Garment Package in Suppressing Transient Heat Exchange Processes. Fibres \& Textiles in Eastern Europe, 14 (2), 55-58.

[7] Nazir, A. et al. (2014) Effect of Knitting Parameters on Moisture Management and Air Permeability of Interlock Fabrics. AUTEX Research Journal, 14 (1), 39-46.

[8] Ogulata, R.T., Mavruz, S. (2010) Investigation of Porosity and Air Permeability Values of Plain Knitted Fabrics. Fibres\&Textiles in Eastern Europe, 18 (5), 82-90.

[9] Mikučionienè D., Laureckienè G. (2009) The Influence of Drying Conditions on Dimensional Stability of Cotton Weft Knitted Fabrics Investigation on Thermal properties of Double- Layered Weft Knitted Fabrics. Materials Science
(Medziagotyra), 15 (1), 64-68.

[10] Abramavičiūtè J., Mikučioniené D., Čiukas R. (2011) Static Water Absorption of Knits from Natural and Textured Yarns. Fibres\&Textiles in Eastern Europe, 19 (3), 60-63.

[11] Fangueiro, R. et al.(2010) Wicking Behaviour and Drying Capability of Functional Knitted Fabrics. Textile Research Journal, 80 (15), 1522-1530.

[12] Cui Z., Zhang W. (2009) Study of the Effect of Material Assembly on the Moisture and Thermal Protective Performance of Firefighter Clothing. Fibres\&Textiles in Eastern Europe, 17 (6), 80-83.

[13] Mikučioniené D., Baltušnikaité J., Milašius R. (2011) Influence of the Number of Yarns in a Loop on the Flammability of Knits. Fibres\&Textiles in Eastern Europe, 19 (6), 71-74.

[14] Mikučioniené D. et al. (2012) Influence of Plain Knits Structure on Flammability and Air Permeability. Fibres\&Textiles in Eastern Europe, 20 (5), 66-69.

[15] Spencer D.J. Knitting Technology: a Comprehensive Handbook and Practical Guide. Cambridge, 2001. 